\title{
De la Biblioteca de Babel a la casa de papel
}

\author{
From La Biblioteca de Babel to La Casa de Papel \\ Da Biblioteca de Babel para a moradia de papel
}

\section{Carmen Perilli}

UNIVERSIDAD NACIONAL DE TUCUMÁN/CONICET, ARGENTINA

Profesora titular de Literatura Latinoamericana, Universidad Nacional de

Tucumán (UNT); Doctora en Letras por la misma universidad. Directora

de la revista Telar. Entre sus libros se destacan Imágenes de la mujer en

Carpentier y García Márquez (UNT, 1991), Historiografía y ficción en

la narrativa latinoamericana (UNT, 1995), Países de la memoria y del

deseo: Borges y Fuentes (UNT, 2004) y Catálogo de ángeles mexicanos:

Elena Poniatowska (Beatriz Viterbo, 2006). Es co-compiladora de

Fábulas del género (Beatriz Viterbo, 1995) y de Siluetas de papel

(Corregidor, 2011). Correo electrónico: carmenperilli@gmail.com

\footnotetext{
Artículo de reflexión

El presente artículo se origina en el proyecto de investigación sobre Rrepresentaciones de autor en la narrativa latinoamericana, Universidad Nacional de Tucumán(UNT).

Documento accesible en línea desde la siguiente dirección: http://revistas.javeriana.edu.co

doi:10.11144/Javeriana.CL18-36.bbcp
} 


\section{Resumen}

Este ensayo trabaja las representaciones de la biblioteca en "La Biblioteca de Babel" de Jorge Luis Borges, Cien años de soledad de Gabriel García Márquez y La casa de papel de Carlos María Domínguez. Para Borges la biblioteca es una institución intemporal e infinita que encierra la totalidad de la lengua y metáfora del universo. García Márquez le reserva un lugar reducido: un cuarto donde se encuentran libros antiguos en idiomas extraños y un manuscrito profético, doble de la novela. En La casa de papel, un profesor a quien un extraño ejemplar de Conrad lleva de Cambridge a Montevideo se encuentra con la trágica historia de un bibliófilo que, perdido el catálogo, construye una casa de papel en la playa pero no logra aniquilar la memoria de la biblioteca.

Palabras clave: archivo; biblioteca; espacios; libro; representaciones; Jorge Luis Borges; Gabriel García Márquez; Carlos María Domínguez

\section{Abstract}

In the post-neoliberal context in which we are, the paradigm that governs the constellation of the Latin American cultural studies has become outdated and it needs to be modified. The author argues that the currents of thought associated with the exploration of the concept of posthegemony represent, in today's Latin Americanism, a form of academic ultraleftism. In this article some of the intellectual and political implications of that position are discussed in relation to the new governments of the "pink tide".

Keywords: posthegemony, ultraleftism, Latin Americanism, cultural studies; Jorge Luis Borges; Gabriel García Márquez; Carlos María Domínguez

\section{Resumo}

No contexto pós-neoliberal no que encontramos-nos o paradigma que governa a constelação dos estudos culturais latino-americanos tem virado anacrônico e precisa de modificações. $\mathrm{O}$ autor sustém que as correntes vinculadas à exploração do conceito de póshegemonia representam, dentro do latino-americanismo atual, uma forma de ultraesquerdismo acadêmico. Neste artigo são analisadas algumas implicações intelectuais e políticas de tal posição em relação com os novos governos da "maré rosada".

Palavras-chave: pós-hegemonia, ultraesquerdismo, latinoamericanismo, estudos culturais; Jorge Luis Borges; Gabriel García Márquez; Carlos María Domínguez

RECIBIDO: 7 DE OCTUBRE DE 2013. APROBADO: 27 DE OCTUBRE DE 2013. DISPONIBLE EN LÍNEA: 30 DE JULIO DE 2014.

\section{Cómo citar este artículo:}

Perilli, Carmen. "De la Biblioteca de Babel a la casa de papel". Cuadernos de Literatura

18.36 (2014): 281-295. http://dx.doi.org/10.11144/Javeriana.CL18-36.bbcp 
"La biblioteca es ilimitada y periódica. Si un eterno viajero la atravesara en cualquier dirección, comprobaría al cabo de los siglos que los mismos volúmenes se repiten en el mismo desorden (que, repetido, sería un orden: el Orden)"

JORGE LUIS BORGES, "LA BIBLIOTECA DE BABEL"

\author{
"El cuarto se hizo entonces vulnerable al polvo, al calor, al \\ comején, a las hormigas coloradas, a las polillas que habían de convertir \\ en aserrín la sabiduría de los libros y los pergaminos" \\ GABRIEL GARCÍA MÁRQUEZ, CIEN AÑOS DE SOLEDAD
}

"Pero la casa de papel, en una lejana playa del sur, terminó por hacerme sensible a esa línea de sombra: una dimensión ciega que reúnen en un extraño juguete, la voluntad y el cuerpo de la letra impresa"

CARLOS MARÍA DOMÍNGUEZ, LA CASA DE PAPEL

LAS B I BLI OTECAS APARECEN con frecuencia en las páginas de la narrativa latinoamericana del siglo XX. En un continente donde históricamente hay una relación problemática entre oralidad y escritura, la letra, en el exceso o la negación, se transforma en uno de los temas reiterados en las ficciones. Me propongo leer los tropos de la biblioteca en tres textos de la literatura latinoamericana: "La Biblioteca de Babel" de Jorge Luis Borges (1949), Cien años de soledad de Gabriel García Márquez (1967) y La casa de papel de Carlos María Domínguez (2004).

Las tres obras ponen en escena ficciones en tiempos distintos de un sitio que, en todos los casos, es masculino. El guardián, el lector, el intérprete o el propietario es varón e ilustrado. En Michel de Certeau, que habla de "relatos de espacio" que atraviesan y organizan lugares, dos elementos, memoria y orden, correlatos de tiempo y espacios, se presentan como consustanciales en el ámbito de los libros ${ }^{1}$. Los relatos, según De Certeau, "efectúan pues un trabajo que, incesantemente, transforma los lugares en espacios o los espacios en lugares" (130).

$1 \quad$ "El espacio es al lugar lo que se vuelve la palabra al ser articulada, es decir cuando queda atrapado en la ambigüedad de una realización, transformado en un término pertinente de múltiples convenciones, planteado como el acto de un presente (o de un tiempo), y modificado por las transformaciones debidas a contigüidades sucesivas. A diferencia del lugar, carece pues de la univocidad y de la estabilidad de un sitio "propio"' (Certeau 129). 
Una biblioteca puede considerarse un sistema de cuerpos peculiares, en un doble sentido material y simbólico, que conforman una zona de relaciones en el orden de la cultura. En Occidente un largo proceso de mitificación que se inició con el libro sagrado naturalizó la condición histórica del libro. Nuestras ficciones trabajan las heterogéneas fábulas que se tejen alrededor del libro, la lectura y el lector, la escritura y el escritor. Las identidades textuales aparecen como construcciones de un dominio signado por el cambio que se reconfigura constantemente inscribiendo territorios y temporalidades ${ }^{2}$. La lectura de estas identidades supone la aceptación del carácter narrativo y relacional de las mismas. El concepto de obra se aproxima al de archivo en la medida en que da cuenta de las complejas operaciones de la literatura; el autor acepta la cercanía a una condición originaria de lector. Toda una constelación de figuras refieren al libro como significante. Esta poética del espacio apela, de modo constante, al mito, "esa palabra robada y devuelta a otro lugar" en las consideraciones de Roland Barthes.

Las bibliotecas están llenas de fantasmas, en el sentido que lo imagina Jacques Bonnet, y el libro es un espacio delimitado, que contiene distintas temporalidades. Su sitio puede configurar un paraíso o un infierno: "La delgada piel de lo escrito se convierte en un movimiento de estratos, en un juego de espacios" (Certeau iii). La biblioteca une dos gestos, el del lector y el del coleccionista. Si el primero está marcado por la acción, el segundo se caracteriza por el afán de posesión. Las pasiones suscitadas por la escritura pueden ser extremas. Gérard Haddad señala que "en las antípodas del devorador del Libro que lo hace suyo, el incendiario lo vomita con horror, busca erradicarlo, rechaza todavía más su transmisión" (7).

El lector tiene ante sí una doble vida de la obra: el artefacto manufacturado y el transmisor de significado (Littau). Si consideramos los libros como cuerpos materiales, podemos afirmar que sus cuerpos se encuentran sometidos a innovaciones continuas. La bibliomanía y la "biblioclastia" forman parte de la relación del hombre con ellos. El lugar donde un individuo o una sociedad los reúne remite al orden y la importancia que les otorga.

\section{La Biblioteca de Babel}

En el relato "La Biblioteca de Babel" Borges construye uno de sus laberintos más acabados. El orden de los libros nos remite a la finitud en lo sintáctico y a la infinitud en lo semántico. Babel, significante múltiple, remite a la torre con la que los

2 "La identidad sería entonces no un conjunto de cualidades predeterminadas - raza, color, sexo, clase, cultura, nacionalidad, etc.- , sino una construcción nunca acabada, abierta a la temporalidad, la contingencia, una posicionalidad relacional solo temporariamente fijada en el juego de las diferencias" (Arfuch 25). 
hombres, que habían recibido el don de la lengua común, osaron desafiar a Jehová y por cuya construcción se les impuso el castigo de la dispersión de los hombres y la confusión de las lenguas ${ }^{3}$. El término remite a Babilonia y a la mítica Alejandría. Babel representa el desafío de las criaturas, unidas por el mismo código, a la divinidad que no soporta que la emulen y las condena a la dispersión. La fábula encerrada en el posesivo contrasta con el sustantivo "biblioteca", que implica un orbe organizado.

El narrador, fascinado por la existencia de los libros, siente terror frente a la eternidad de la biblioteca: "sospecho que la especie humana - la única- está por extinguirse y que la Biblioteca perdurará: iluminada, solitaria, infinita, perfectamente inmóvil, armada de volúmenes preciosos, inútil, incorruptible, secreta" (Borges 470-471). Si en el orden sintáctico los libros son limitados, en el orden semántico se los puede figurar infinitos. El orden funciona como un conjunto de coacciones que traba y, al mismo tiempo, estimula los hallazgos, con una férrea reglamentación externa que pretende organizar, con una lógica ajena, el mundo de la escritura y la lectura. La lectura aparece como viaje, como recorrido por pasajes en los que la pérdida es una posibilidad. Borges pasa del nivel literal al metafórico y lo amplía hasta el estallido. En "De alguien a nadie", un texto de Otras inquisiciones, el autor entrega las claves de su poética: "La magnificación hasta la nada sucede o tiende a suceder en todos los cultos" (Borges, Obras 738). Y agrega: "Ser una cosa es inexorablemente no ser todas las otras cosas; la intuición confusa de esa verdad ha inducido a los hombres a imaginar que no ser es más que ser algo y que, de alguna manera, es ser todo" (739).

En el mito el significante pasa a formar parte de un sistema semiológico mayor. La biblioteca es metáfora del universo que también puede tomar la forma del Libro y que siempre se conforma como laberinto para el hombre. El cuidador

3 "Era entonces toda la tierra de una lengua y unas mismas palabras. Y aconteció que, como se partieron de oriente, hallaron una vega en la tierra de Shinar, y asentaron allí.

Y dijeron los unos a los otros: Vaya, hagamos ladrillo y cozámoslos al fuego. Se sirvieron de los ladrillos en lugar de piedras y de betún en lugar de argamasa. Y fueles el ladrillo en lugar de piedra, y el betún en lugar de mezcla.

Y dijeron: Vamos, edifiquémonos una ciudad y una torre cuya cúspide llegue hasta el cielo y hagámonos un nombre por si fuéramos esparcidos sobre la faz de la Tierra.

Y descendió Jehová para ver la ciudad y la torre que edificaban los hijos de los hombres.

Y dijo Jehová: He aquí el pueblo es uno y todos estos tienen un mismo lenguaje y han comenzado a obrar y nada les retraerá ahora de lo que han pensado hacer. Ahora pues descendamos y confundamos allí sus lenguas, para que ninguno entienda el habla de su compañero.

Así los esparció Jehová desde allí sobre la faz de toda la Tierra y dejaron de edificar la ciudad. Por esto fue llamado el nombre de ella Babel porque allí confundió Jehová el lenguaje de toda la Tierra y desde allí los esparció sobre la faz de la tierra" (Gn. 11: 1-10). 
puede ser ese mismo dios o puede ser un hombre designado arbitrariamente. Borges, ya ciego, confesó haberse imaginado el paraíso bajo la forma de una biblioteca ahora "alta", "honda" y "ciega". "La Biblioteca de Babel" es incluido en El jardín de senderos que se bifurcan (1942) y posteriormente en Ficciones (1944). En el relato el protagonista central es el espacio arquitectónico, como lo demuestra, con minuciosidad, Cristina Grau:

El universo (que otros llaman la Biblioteca) se compone de un número indefinido, y tal vez infinito, de galerías hexagonales, con vastos pozos de ventilación en el medio, cercados por barandas bajísimas. Desde cualquier hexágono se ven los pisos inferiores y superiores: interminablemente. La distribución de las galerías es invariable. Veinte anaqueles, a cinco largos anaqueles por lado, cubren todos los lados menos dos; su altura, que es la de los pisos, excede apenas la de un bibliotecario normal. Una de las caras libres da a un angosto zaguán, que desemboca en otra galería, idéntica a la primera y a todas. A izquierda y a derecha del zaguán hay dos gabinetes minúsculos. Uno permite dormir de pie; otro, satisfacer las necesidades finales. Por ahí pasa la escalera espiral, que se abisma y se eleva hacia lo remoto. (Borges, Obras 465)

La descripción detallada del edificio permite ver que la clave es la estructura simple del hexágono. Su trascripción literaria abona la sensación de un lugar imposible de formalizar por la abrumadora homogeneidad que obstaculiza cualquier orientación en la travesía por los pasillos. Al recorrido por un paisaje uniforme hay que agregar la superposición en altura. El lector tiene idéntica visión desde cualquier punto, lo que provoca el extravío por la pérdida de instrumentos de referencia. La escalera en espiral es otro de los elementos delirantes ya que "se eleva hacia lo remoto". Borges juega con el centro ausente y la inabarcable dimensión: "En el zaguán hay un espejo, que fielmente duplica las apariencias. Los hombres suelen inferir de ese espejo que la Biblioteca no es infinita (si lo fuera realmente $\mathrm{C}^{\mathrm{a}}$ qué esa duplicación ilusoria?); yo prefiero soñar que las superficies bruñidas figuran y prometen el infinito" (Obras 465$)$.

Sin embargo, la uniformidad es relativa ya que todos los libros son iguales en formato, todos los hexágonos presentan el mismo aspecto salvo que abramos los libros y nos introduzcamos en ellos como lectores, transformando el espacio. El guardián es uno de los custodios del edificio, obsesionado, alguna vez, con la elaboración de un "catálogo de catálogos". Pero la Biblioteca es una esfera cuyo centro cabal es cualquier hexágono; una circunferencia inaccesible que se asemeja a la representación pascaliana del universo. Su eternidad contrasta con la naturaleza informe y caótica de los libros. La organización idéntica de los volúmenes no impide 
que "no haya dos libros idénticos". Toda operación reductora o destructora queda anulada. La Biblioteca lo contiene todo, como la Lengua, y la postulación de un orden no es imposible. La palabra Babel nos remite al mito bíblico y a la ambición de poseer la Lengua y, por extensión, el Conocimiento absoluto.

No puedo combinar unos caracteres que la divina Biblioteca no haya previsto y que en alguna de sus lenguas secretas no encierren un terrible sentido. Nadie puede articular una sílaba que no esté llena de ternuras y de temores; que no sea en alguno de esos lenguajes el nombre poderoso de un dios. Hablar es incurrir en tautologías. (Borges, Obras 470)

Borges imagina su Biblioteca a partir de dos modelos históricos: la biblioteca privada de su padre y la biblioteca pública donde trabajó. La biblioteca aparece como institución social más que como constructo individual, su cuidador, más que poseerla, le sirve a ella. Es el símbolo más acabado de la alta cultura, contiene libros de todas las lenguas e inquieta y provoca a diversas sectas. Como uno de los más perfectos laberintos borgeanos, siempre se puede fantasear con la existencia de un camino hacia el ignoto centro.

\section{El cuarto de Melquíades}

Cien años de soledad propone una peculiar poética de la lectura. En la novela la biblioteca está en un espacio reducido: el cuarto de Melquíades el gitano. Un espacio pequeño dentro de la gran casa familiar, donde se ubica al extranjero y que funciona de modo especular con el taller donde el coronel Aureliano fabrica pescaditos de oro. Esta pieza solo despierta el interés de algunos personajes, todos varones (con excepción de Meme). Son los únicos capaces de comprender su contenido y buscar refugio entre sus paredes. Contiene libros antiguos, en lenguajes herméticos e idiomas perdidos. Esos objetos son ajenos al mundo de Macondo, una comarca oral, aunque repercuten de modo indeleble en su existencia.

Macondo es territorio de voces, donde el lector es un sujeto extraño, se transforma en hermeneuta y traductor. El espacio del libro está ocupado por el manuscrito que remite al Libro. Los personajes femeninos se muestran desinteresados por los secretos del cuarto, aunque Úrsula mande construirlo y Fernanda coloque allí las bacinillas". La matriarca destina al cuarto "los libros casi deshechos por el polvo y las polillas, los quebradizos papeles apretados de

4 Las mujeres son ajenas a este espacio, lo ignoran como Fernanda, que lo utiliza para guardar las bacinillas. Allí esconde Santa Sofía de la Piedad a José Arcadio Segundo cuando lo busca el ejército después de la huelga bananera. 
signos indescifrables" (García Márquez 68). Melquíades garabatea "su literatura enigmática en los pergaminos que llevó consigo y que parecían fabricados en una materia árida que se resquebrajaba como hojaldres" (68). Porque el gitano había dispuesto que debía pasar un siglo de su muerte para que alguien accediera al conocimiento de su sentido.

El coronel Aureliano Buendía no advierte la presencia del fantasma en el cuarto (así como tampoco al fantasma del padre en el castaño). Después de mucho tiempo Aureliano Segundo descubre este lugar intemporal, al que no le hace mella el paso de los años y se estrella con el hermetismo de los manuscritos: "Fue imposible. Las letras parecían ropa puesta a secar en un alambre, y se asemejaban más a la escritura musical que a la literaria" (161). El cuarto permanece fuera de la historia y del deterioro hasta que se encuentra el código. Allí todo parece "reciente" sin acusar el paso del tiempo. José Arcadio Segundo, atrapado por el miedo de la matanza, convive con el fantasma de Melquíades y logra clasificar las letras de los pergaminos antes de su desaparición.

La historia contenida en los papeles no está destinada a cualquiera, exige un saber misterioso. El espectro que lo posee se relaciona con el misterio del cuarto y con la librería del sabio, otro extranjero de pasó por el pueblo. Melquíades y su cuarto se desdoblan en el sabio catalán y la librería. Los dos escriben y custodian los libros. El erudito también está entregado a una misteriosa y excluyente escritura en catalán y vende "incunables", cuya existencia contrasta con la realidad delirante de Macondo, entregado a la falsa modernización que trae la Compañía Bananera. La librería, un espacio de cultura en medio de una realidad hostil, no está vinculada al conocimiento modernizador sino al saber antiguo.

Más que una librería, aquella parecía un basurero de libros usados, puestos en desorden en los estantes mellados por el comején, en los rincones amenazados de telaraña, y aun en los espacios que debieron destinarse a los pasadizos. En una larga mesa, también agobiada de mamotretos, el propietario escribía una prosa incansable, con una caligrafía morada, un poco delirante, y en hojas sueltas de cuaderno escolar. Tenía una hermosa cabellera plateada que se le adelantaba en la frente como el penacho de una cacatúa, y sus ojos azules, vivos y estrechos, revelaban la mansedumbre del hombre que ha leído todos los libros. (310)

Las actividades "culturales" y literarias están reducidas al grupo de amigos de Gabriel, entre los que se encuentra Aureliano Babilonia. Cuando el hijo de Meme consigue el diccionario de sánscrito, una suerte de anacronismo exótico, puede iniciar la lectura de los pergaminos. Al partir hacia su tierra el sabio, en un 
gesto que lo diferencia de Melquíades, se lleva sus papeles intocados en el barco. El librero es uno de los primeros en reconocer el "fatalismo enciclopédico".

Aureliano Babilonia (cuyo apellido remite a la pluralidad de Babel) aprende solo varias lenguas. Melquíades lo abandona en cuanto adquiere la clave de lectura y puede dedicarse a ella ${ }^{5}$. Cuando el muchacho atraído por Amaranta Úrsula se aleja del cuarto y descuida su labor, la tragedia se precipita sobre la deteriorada casa. La escritura no cifra un saber ignoto, sino la historia de Macondo y la única probabilidad de futuro.

La lectura es la única oportunidad que tienen los Buendía de recuperar la identidad familiar. El manuscrito funciona como el archivo, la máquina de la memoria que intentó construir el fundador y que acabó por redactar el exótico forastero. Encierra, al igual que la Biblioteca de Borges, una escritura profética hacia el pasado. La tarea de desciframiento de los manuscritos no permite distracciones ya que se corre el riesgo de que "la memoria se petrifique". El último vástago Buendía acaba, como los pergaminos, hecho un pellejo. El niño muere, puro pellejo "inscripto" por las picaduras de las hormigas, mientras los manuscritos perseveran intactos. En medio de ese cataclismo Aureliano Babilonia, "de pie, sin la menor dificultad, como si hubieran estado escritos en castellano bajo el resplandor deslumbrante del mediodía, empezó a descifrarlos en voz alta. Era la historia de la familia escrita por Melquíades hasta en sus detalles más triviales, con cien años de anticipación" (349).

La última escena de Cien años de soledad es una escena de lectura y el manuscrito cifrado en versos refleja como en un espejo la génesis y la destrucción de Macondo. Antes de llegar al verso final Aureliano Babilonia "ya había comprendido que no saldría jamás de ese cuarto, pues estaba previsto que la ciudad de los espejos (o los espejismos) sería arrasada por el viento y desterrada de la memoria de los hombres en el instante en que Aureliano Babilonia acabara de descifrar los pergaminos" (351).

La lectura es un acto radical ya que la letra cifra la historia de la comunidad y del individuo. Es un saber importado, proveniente de un mundo ajeno a Macondo. El cuarto, que es de algún modo el manuscrito, desaparece con el pueblo.

5 "Aureliano avanzaba en los estudios del sánscrito mientras Melquíades iba haciéndose cada vez menos asiduo y más lejano, esfumándose en la claridad radiante del mediodía. La última vez que Aureliano lo sintió era apenas una presencia invisible que murmuraba: 'He muerto de fiebre en los médanos de Singapur'. El cuarto se hizo entonces vulnerable al polvo, al calor, al comején, a las hormigas coloradas, a las polillas que habían de convertir en aserrín la sabiduría de los libros y los pergaminos" (302). 
El lector está condenado a desvanecerse en cuanto el libro termina. El saber sobre la realidad, la suma de las memorias del archivo, está contenida en sus páginas.

\section{La casa de papel}

Carlos María Domínguez arma una ficción especulativa, una reflexión sobre el destino de los libros y los lectores. Mientras narra la historia de un curioso lector uruguayo, Carlos Brauer, despliega un abanico de posibles conductas y situaciones extremas en relación con los libros, desde influencias de autores hasta accidentes fatales, pasando por ritos, fetiches, obsesiones, fantasías alrededor de la biblioteca.

En una nota de Ángel Berlanga, Domínguez cuenta que, antes de escribir el libro, hizo una investigación sobre los vínculos que los lectores entablan con sus bibliotecas domésticas y que se sumergió en el extraño mundo de los bibliófilos. Así dio con "exquisitos que para leer un capítulo necesitan tener veinte libros a mano", expertos en preservación obsesionados ante posibles ataques de bichos, polvos y humedades, tipos que son capaces de regalar el auto para hacerles espacio a los libros en el garaje.

La pregunta fue ¿de qué modo los libros cambian la vida de las personas y viceversa, de qué modo las personas también cambian el destino de los libros, tanto en lo simbólico o cultural como en lo físico? Ese recorrido abarca a la lectura desde el placer del conocimiento, pero también desde su sensualidad, el goce de apreciar una buena edición, el papel, las letras como dibujos, las buenas ediciones. (Berlanga 2)

En La casa de papel, el narrador autobiográfico es un profesor de literatura. Una colega, Bluma Lennon, muere en un misterioso accidente atropellada mientras lee los poemas de Emily Dickinson. Su sorprendente muerte, atribuida a los libros, agita el mundo académico de la Universidad de Cambridge. El narrador, que ocupa su lugar, recibe un maltrecho libro devuelto a la difunta, un "desquiciado y viejo" ejemplar de La línea de sombra de Joseph Conrad. En la primera página hay una misteriosa dedicatoria de Bluma donde se lee: "Lamento ser un poco bruja y haber advertido enseguida: nunca harás nada capaz de sorprenderme, Junio 8 de 1996". La inscripción se relaciona con las líneas del misterioso prólogo de La línea de sombra: "El mundo de los vivos encierra ya por sí solo bastantes maravillas y misterios; maravillas y misterios que obran de modo tan inexplicable sobre nuestras emociones y nuestras inteligencias, que ello bastaría casi a justificar que pueda concebirse la vida como un sortilegio" (Conrad 2). 
El deterioro resulta difícil de explicar ya que el libro parece haber estado expuesto al agua y a la tierra. El enigma estimula la búsqueda de Carlos Brauer, un bibliófilo rioplatense, que ha desaparecido de Montevideo. A lo largo de la investigación el protagonista sentirá inquietud frente a ese objeto que refiere, amenazante, a su propia biblioteca: "A menudo es más difícil deshacerse de un libro que obtenerlo. Se adhieren con un pacto de necesidad y olvido, tal como si fueran testigos de un momento en nuestras vidas al que no regresaremos... Sucede que, al fin el tamaño de la biblioteca importa" (Domínguez 19). El ajado ejemplar es ominosa advertencia de que, de modo herético, toda biblioteca puede ser destruida. La ficción, con fuerza ensayística, reflexiona sobre lectores y libros. Si en la primera página leemos: "Los libros cambian el destino de las personas", en la página 67 se afirma que las personas también cambian el destino de los libros.

En el viaje a tierras rioplatenses el narrador emprende la búsqueda del misterioso Brauer y se interna en el laberíntico mundo de libreros y coleccionistas de Buenos Aires, donde frecuenta a sus amigos escritores preocupados por encontrar la fama y se siente intimidado ante la proliferación alarmante de publicaciones. Las librerías exhiben una exuberancia babélica, la impresión de libros parece haberse desbordado. "En Buenos Aires, los libros se habían convertido en centro de una alucinada guerra de estrategias, talento de ubicuidad y poder" (26).

El dueño de una de las mejores librerías de ediciones antiguas de Montevideo conoció a Brauer, quien era un bibliófilo o lector, no solo coleccionista. Lo conduce a su colega Agustín Delgado, quien conoce la historia del desaparecido. Delgado, temeroso y reticente, le narra el trágico periplo de su amigo. El coleccionismo de Brauer se había tornado irrefrenable y su biblioteca creció hasta cercarlo, reduciéndolo a un lugar en el baño de la casa. Incapaz de desprenderse de sus obras, perdía su propio espacio y se movía entre oscuros pasadizos de estantes que oprimían su cuerpo.

La hybris del lector/coleccionista, transformado de bibliófilo en biblioclasta, convertido en voraz caníbal de papeles impresos, acaba por tener su castigo ${ }^{6}$. El nomadismo de lector desaparece y se trastoca en ansia de propietario/prisionero de un mundo que comienza a asfixiarlo. Las velas encendidas para ambientar la lectura de un texto renacentista incendian el fichero. Sin el orden, todo está perdido. La locura por los libros acaba por tragar al lector. Como señala el horrorizado

6 Gérard Haddad se refiere a la idea de comer libros como una de las fantasías del biblioclasta. 
Delgado: "Un hombre puede conquistar muchas lecturas, pero un conquistador se halla obligado a administrarlas" $(47)^{7}$.

El fetichismo de Brauer es excesivo y su biblioteca desata una ambición incontrolable ya que su deseo no acepta límites y atenta contra la posibilidad de ordenar y controlar el mundo de los libros. En su intento por organizar sus volúmenes, su pasión lo empujó a cambiar el fichero temático por un complejo fichero "afectivo" en el que introduce una dimensión subjetiva en el archivo: "Insistía en que los libros afines merecían permanecer bajo otro orden que el de la vulgaridad temática" (49).

Los libros para Brauer acaban por convertirse en seres vivos, en la cama o en la mesa. Al intentar reproducir el clima contenido en las páginas en la escena de lectura, los cirios incendian el catálogo. La pérdida del inventario implica el extravío de la memoria y la locura. Después del incendio viajó a Monterrey y conoció a Bluma, cuya muerte predijo a Delgado, a quien describió como "una de esas académicas fogosas y petulantes, que todo lo revisten de citas literarias y, si les toca morir preferirían ser atropelladas mientras leen a Emily Dickinson" (58).

La respuesta a la pérdida del archivo es desmesurada y monstruosa. Enfrentado a la imposibilidad de rehacer el fichero, Brauer decide destruirlo en un gesto de apropiación. Afirma su poder sobre esos objetos que se rebelan trasladando los libros a una playa lejana y transformándolos en ladrillos de una casa de papel que construye ante los espantados ojos de los lugareños ${ }^{8}$. Arrancados de su lugar "natural" los volúmenes parecen aceptar un nuevo orden en su función de material de una casa. La biblioteca se convierte en "una obra destruida dentro de otra. No solo encerrada. Aniquilada en el cemento" (65). Brauer edifica una sólida casa con los libros, una suerte de siniestro laberinto donde quedan atrapados los textos.

Bajo la mirada, entre piadosa e indiferente del albañil que hacía la mezcla, se dedicó a seleccionar, de la montaña de libros arrojada por el carro sobre la arena limpia y blanca, los libros que debían protegerlo del viento, la lluvia, la inclemencia del invierno. No le importaba ya la amistad o enemistad entre los autores, las afinidades o contradicciones entre Spinoza, la botánica del Amazonas y la Eneida de Virgilio; si las encuadernaciones eran buenas o mediocres, si

7 Reconocemos en la ficción de Carlos María Domínguez muchos de los conceptos expuestos por Michel de Certeau en La invención de lo cotidiano.

8 La lectura carece de lugar. Michel de Certeau se refiere a una lectora en estos términos: "¿qué lugar la cautivaba, que era y sin embargo no era el que aparecía en la imagen vista? Y así es para el lector: su lugar no está aquí o allá, uno o el otro, pero tampoco ni uno ni lo otro, a la vez dentro y fuera, pierde uno y otro al mezclarlos, al asociar textos yacentes de los cuales él es el despertador y el huésped, pero nunca el propietario" (187). 
tenían grabados o láminas, estaban intonsas o se trataba de incunables. Apenas la proporción de cada volumen, el grosor, la fortaleza de sus tapas para resistir la lechada de cal, cemento y arena. El albañil presentó el tomo enciclopédico sobre el ángulo de uno de los postes y contó los volúmenes de la colección, y debió alinearlos sobre el hilo que le servía de guía. (62-63)

El narrador intrigado encuentra los restos de la casa en el médano. Los lugareños le cuentan que vieron a Brauer desesperado, gritando el nombre de un libro y acabando con todo. Una carta de Bluma reclamando La línea de sombra despierta los fantasmas que, encerrados en las paredes, amenazan la existencia del bibliófilo. La certeza de la presencia del texto entre el cemento se tornó apabullante. Es la memoria no el olvido lo que derrumba todas sus defensas ya que, aunque intenta destruir el libro, no puede destruir su memoria. La ficción de Joseph Conrad está presente desde las primeras páginas que vuelven una y otra vez sobre la idea de "la línea de sombra" expuesta en el prólogo del libro de Conrad.

Sí; caminamos, y el tiempo también camina, hasta que, de pronto, vemos ante nosotros una línea de sombra advirtiéndonos que también habrá que dejar atrás la región de nuestra primera juventud. Este es el periodo de la vida en que suelen sobrevenir aquellos momentos de que hablaba. ¿Cuáles? ¡Cuáles van a ser!: esos momentos del hastío, de cansancio, de descontento; momentos de irreflexión. (4)

En la enigmática dedicatoria a Lenin, en la llegada del narrador a Montevideo, su propio punto de partida, está el desafío del cruce del umbral. La historia de Brauer amenaza su propio universo: "La línea de sombra me había conducido a un páramo de aguas enrarecidas" (33). La presencia del límite, entre los libros y los hombres, se asemeja al contraste entre el barco y la ciudad frente al mar, "dos mundos incrustados, uno en el otro, que los volvía, de algún modo, inverosímiles" (33). Brauer busca en Rocha "un lugar sin sombra" (6o). La casa entre la laguna y el mar pretende armar un muro que contenga tanto a la cultura como a la naturaleza. Las tumbas del cementerio donde está enterrada Bluma se parecen a los volúmenes sellados y rígidos. Carlos Brauer es interpelado no por el olvido sino por la memoria. El reclamo del ejemplar llevó a Brauer a destruir la casa, a liberarse del laberinto de libros: "El libro no sorprendió a Bluma, demasiado tarde en la lluvia, y no había sido mejor para ella. Pero un hombre había atravesado, con brutalidad, desazón y certeza, su línea de sombra" (86).

La casa de papel plantea distintas preguntas. Entre ellas se me ocurren: ¿qué es un libro? ¿Qué es un lector? ¿Se puede ser dueño de un libro? ¿Qué es 
una biblioteca? ¿Cuál es el futuro del papel? ¿Qué pasa con el archivo? Atrapado entre la amenaza de la censura y el poderío del mercado, expuesto a la naturaleza y la historia, el libro continúa interpelando nuestra memoria. La biblioteca no está inmóvil, desde la doble condición de objeto, el texto perdura. Nos encontramos con un regreso al mundo natural que se hace imposible ${ }^{9}$.

Las ficciones que hemos recorrido arman diversas "bibliotecas" o lugares donde se guardan los libros. Borges formula una fábula donde la Biblioteca es una institución intemporal e infinita que encierra la totalidad de la cultura, que es, en última instancia, la totalidad de la lengua. En ese laberinto gigantesco el lector es un guardián de un saber que lo excede, proveniente de una fuente enigmática y exterior. Esa Biblioteca es metáfora del universo y se corresponde con una concepción de la cultura basada en el prestigio del libro impreso, apoyada por la tradición de la literatura occidental. Gabriel García Márquez reserva para los libros un lugar reducido: un cuarto. En ese cuarto se encuentran libros antiguos, en idiomas extraños, pero, sobre todo, un manuscrito profético, suerte de doble de la novela. Las narraciones circulan en el mundo exterior al cuarto, un mundo fundamentalmente oral. La librería tampoco se encuentra totalmente inserta en Macondo. Producto de la modernización bananera, permanece ajena a ella, es una librería de incunables, de un sabio que escribe en catalán un manuscrito que nadie leerá. Curiosamente, el manuscrito encerrado en el cuarto encierra los relatos de la historia familiar. García Márquez, que intenta reformular una cultura regional, no desdeña el peso de la escritura, aunque la encierra en un lugar acotado. Pero sobre todo otorga un espacio definitivo a la lectura. Aureliano es, ante todo, un lector.

En Carlos María Domínguez atisbamos el pasaje entre el siglo Xx y el siglo XXI donde el mundo de los libros se encuentra amenazado por grandes cambios. La casa de papel es un texto posmoderno que afirma y deconstruye la idea tradicional de biblioteca. Todo depósito de libros, tanto bibliotecas como librerías, puede estallar por desmesura. En ese horizonte el intento de erigir una casa de papel puede ser ilusorio, un momento imposible. Lo que perdura es la memoria de los libros más allá de la consistencia de los mismos como artefacto y del lugar en que se los encierre. En última instancia los fantasmas de la biblioteca están dentro de los libros y de los lectores. Los biblioclastas nada pueden hacer contra ellos.

9 Cuando me hallaba en la etapa final del trabajo me encontré con el libro de Jacques Bonnet y, con sorpresa, descubrí que consideraba como paradigmática la novela de Domínguez. 


\section{Obras citadas}

Arfuch, Leonor. "Problemáticas de la identidad". Identidades, sujetos y subjetividades. Comp. Arfuch. Buenos Aires: Prometeo, 2005. 21-43.

Barthes, Roland. Mitologías. México: Siglo XXI, 1982.

Berlanga, Ángel. "No muerden pero...". Radar Libros, diario Página/12 domingo 9 de octubre de 2004. Web. 6 de octubre de 2013.

Bonnet, Jacques. Bibliotecas llenas de fantasmas. Barcelona: Anagrama, 2010.

Borges, Jorge Luis. "Autobiographical Notes". The New Yorker 19 de septiembre de 1970: 41-99.

-. Obras completas. Buenos Aires: Emecé, 1974.

Certeau, Michel de. Las artes del hacer. México, D.F.: Universidad Iberoamericana, 2004. Tomo 1 de La invención de lo cotidiano.

Conrad, Joseph. La línea de sombra. Barcelona: Seix Barral, 1985.

Domínguez, Carlos María. La casa de papel. Buenos Aires: Alfaguara, 2004.

García Márquez, Gabriel. Cien años de soledad. Buenos Aires: Sudamericana, 1971.

Eco, Umberto. La búsqueda de la lengua perfecta. Barcelona: Crítica, 1999.

Grau, Cristina. Borges y la arquitectura. Madrid: Cátedra, 1989.

Haddad, Gérard. Los biblioclastas. El mesías y el auto de fe. Buenos Aires: Ariel, 1993.

Littau, Karin. Teorías de la lectura. Libros, cuerpos y bibliomanía. Buenos Aires: Manantial, 2008.

Perilli, Carmen. Imágenes de la mujer en Carpentier y García Márquez.

Tucumán: Universidad Nacional de Tucumán, 1991. 